\title{
Zinc(II)-Catalyzed Chemoselective Reduction of Amides to Amines
}

Synthesis

Key words

amide reduction

silanes

zinc

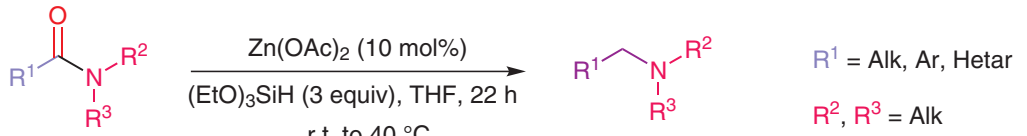

Examples:

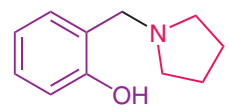

$87 \%$ yield

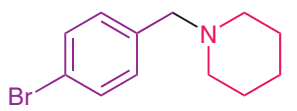

$97 \%$ yield

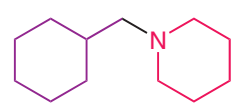

$86 \%$ yield

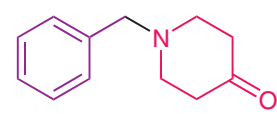

$83 \%$ yield<smiles>CN(C)Cc1ccc([N+](=O)[O-])cc1</smiles>

$85 \%$ yield<smiles>COC(=O)c1ccc(CN2CCCCC2)cc1</smiles>

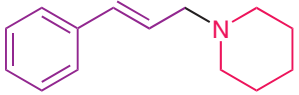

$78 \%$ yield

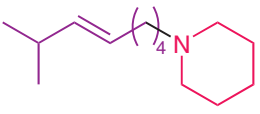

$87 \%$ yield
Significance: The catalytic reduction of amides to amines is a highly desirable transformation in organic synthesis. For the first time, an efficient reduction of tertiary amides with unprecedented chemoselectivity and unique tolerance to functional groups is reported. Amides can be selectively reduced in excellent yields in the presence of ester, nitro, cyano, azo substituents, or even a ketone.
Comment: The role of zinc acetate is not the activation of the amide carbonyl, but rather the activation of the silane with the formation of a complex hydride species. All kinds of tertiary amides can be successfully reduced. For benzamides the reaction rate increases when electron-withdrawing groups are present. Some other silanes, such as $(\mathrm{EtO})_{2} \mathrm{MeSiH}$ and $\mathrm{Ph}_{2} \mathrm{SiH}_{2}$, can also be used. 